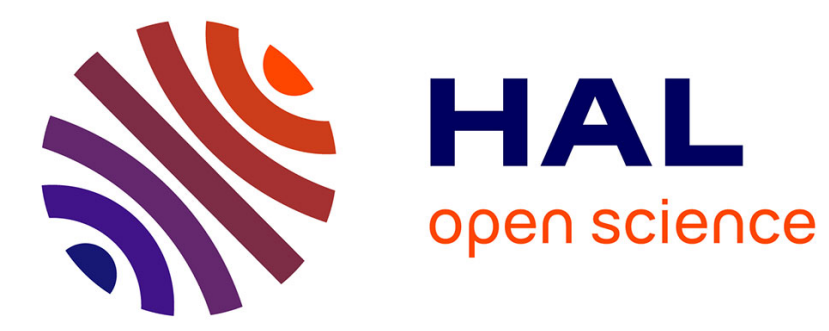

\title{
Mapping Urban Methane Sources in Paris, France
}

Sara M Defratyka, Jean-Daniel Paris, Camille Yver-Kwok, Julianne M

Fernandez, Piotr Korben, Philippe Bousquet

\section{To cite this version:}

Sara M Defratyka, Jean-Daniel Paris, Camille Yver-Kwok, Julianne M Fernandez, Piotr Korben, et al.. Mapping Urban Methane Sources in Paris, France. Environmental Science and Technology, 2021, 55 (13), pp.8583 - 8591. 10.1021/acs.est.1c00859 . hal-03295187

\section{HAL Id: hal-03295187 \\ https://hal.science/hal-03295187}

Submitted on 21 Jul 2021

HAL is a multi-disciplinary open access archive for the deposit and dissemination of scientific research documents, whether they are published or not. The documents may come from teaching and research institutions in France or abroad, or from public or private research centers.
L'archive ouverte pluridisciplinaire HAL, est destinée au dépôt et à la diffusion de documents scientifiques de niveau recherche, publiés ou non, émanant des établissements d'enseignement et de recherche français ou étrangers, des laboratoires publics ou privés.

\section{(ㅇ)(1) $\$$}

Distributed under a Creative Commons Attribution - NonCommercial - NoDerivatives 44.0 


\title{
Mapping Urban Methane Sources in Paris, France
}

\author{
Sara M. Defratyka,* Jean-Daniel Paris, Camille Yver-Kwok, Julianne M. Fernandez, Piotr Korben, \\ and Philippe Bousquet
}

Cite This: Environ. Sci. Technol. 2021, 55, 8583-8591

Read Online

ACCESS | Lلlll Metrics \& More | 回 Article Recommendations | st Supporting Information

ABSTRACT: Megacities, with their large and complex infrastructures, are significant sources of methane emissions. To develop a simple, low-cost methodology to quantify these globally important methane sources, this study focuses on mobile measurements of methane $\left(\mathrm{CH}_{4}\right)$ and its isotopic composition in Paris. Data collected between September 2018 to March 2019 resulted in 17 days of measurements, which provided spatial distribution of street-level methane mixing ratios, source type identification, and emission quantification. Consequently, 90 potential leaks were detected in Paris sorted into three leak categories: natural gas distribution network emissions (63\%), sewage network emissions (33\%), and emissions from heating furnaces of

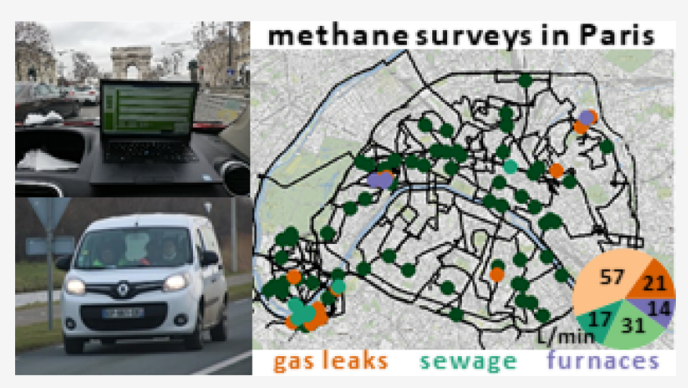
buildings (4\%). The latter category has not previously been reported in urban methane studies. Accounting for the detectable emissions from the ground, the total estimated $\mathrm{CH}_{4}$ emission rate of Paris was 5000 $\mathrm{L} / \mathrm{min}(190 \mathrm{t} / \mathrm{yr})$, with the largest contribution from gas leaks $(56 \%)$. This ranks Paris as a city with medium $\mathrm{CH}_{4}$ emissions. Two areas of clusters were found, where $22 \%$ and $56 \%$ of the total potential emissions of Paris were observed. Our findings suggest that the natural gas distribution network, the sewage system, and furnaces of buildings are ideal targets for street-level $\mathrm{CH}_{4}$ emission reduction efforts for Paris.

\section{INTRODUCTION}

Atmospheric methane $\left(\mathrm{CH}_{4}\right)$ is a potent greenhouse gas that is emitted by a large number of sources, both anthropogenic (e.g., fossil fuels, agriculture, and waste) and natural (e.g., wetlands, freshwaters, termites, and wildfires). Globally and regionally, $\mathrm{CH}_{4}$ emissions are still poorly quantified per sector, leading to emissions uncertainties for anthropogenic and natural sources ( $20 \%$ to $50 \%$ and $50 \%$ to $100 \%$, respectively). ${ }^{1}$ Such uncertainties reflect emission factors and activity data discrepancies, which are used not only for emission quantification, but also for hypothesizing the distribution and magnitude of sectoral emissions. ${ }^{1,2}$ These discrepancies point toward a need to better constrain emissions at a local-scale. Moreover, a better understanding of $\mathrm{CH}_{4}$ emissions spatially and temporally is a mandatory path to achieve effective mitigation strategies.

Urban and suburban areas compose a complex environment, where different sources of $\mathrm{CH}_{4}$ coexist: heating systems (including oil and natural gas networks, domestic networks, and individual combustion systems), landfills, wastewater, and road transport. ${ }^{3-5}$ Therefore, an important matter to address is the need for a better understanding of the contribution of urban $\mathrm{CH}_{4}$ to global emissions.

The complexity and imbrication of city methane sources requires specific observations tools and strategy. Mobile observation approaches provide powerful independent information to constrain emissions and improve inventories at the local scale, and to contribute to reduce uncertainties on emissions at larger scales. Mobile measurements have been successfully used to detect leaks in different cities, helping to prioritize mitigation strategies and verifying existing inventories. $^{5-8}$ Combining mobile concentration measurements with chemical fingerprinting, such as determining stable isotopic signatures of $\mathrm{CH}_{4}$, enables the partitioning of methane emissions by source type. ${ }^{4,5,9-13}$ This allows for the identification and attribution of the source emitters in urban environments.

Globally, in the case of isotopes, more depleted $\delta^{13} \mathrm{CH}_{4}$ values $(-80 \%$ to $-40 \%$ ) (median $\sim-62 \%$ ) are signatures of microbial sources, which are highly selective for ${ }^{12} \mathrm{C} .{ }^{5,9,11,12}$ In contrast, methane from fossil fuels typically varies between $-75 \%$ and $-25 \%$ (median $\approx-44 \% 0$ ) and methane from pyrogenic sources varies between $-35 \%$ and $-7 \% 0^{5,9,11,12}$ (median $\approx-22 \%$ ). In the case of the region Ile-de-France (IDF), based on data from surveys conducted between 2012 and 2015, when $\mathrm{CH}_{4}$ enhancements were measured downwind from sources, narrower signature ranges were found: from $-55.3 \pm 0.1 \%$ o to $-51.9 \pm 0.1 \%$ o for wastewater treatment

Received: February 5, 2021

Revised: April 9, 2021

Accepted: April 9, 2021

Published: June 23, 2021

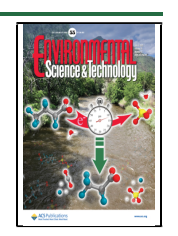




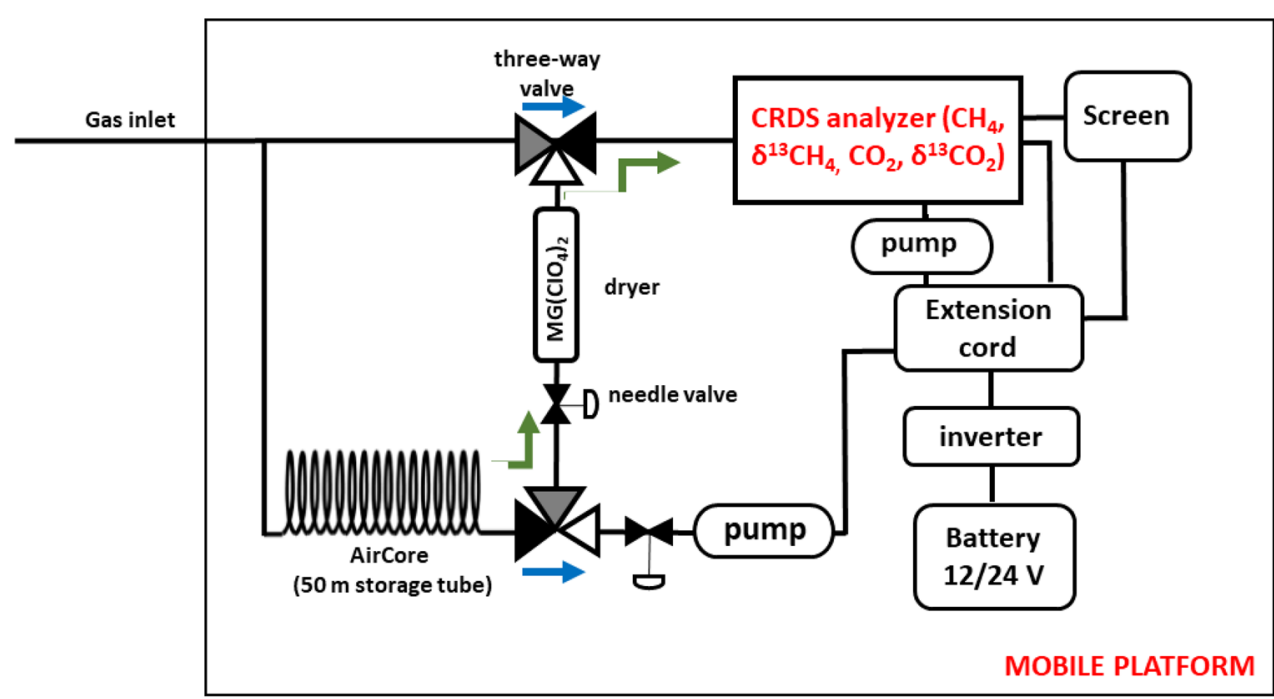

Figure 1. Scheme of mobile measurement setup. The blue arrows show the airflow in monitoring mode. The green arrows show the airflow in the replay mode.

plants (WWTP) and from $-43.4 \pm 01 \%$ to $-33.8 \pm 01 \% 0^{14}$ for natural gas storage facilities.

In 2015, according to the Air quality agency of Ile-de-France (AIRPARIF), the total estimated $\mathrm{CH}_{4}$ emissions from IDF were $30 \mathrm{kt} /$ year. ${ }^{15}$ The AIRPARIF emission inventory for the region (including Paris city) uses a bottom-up technique based on sectoral approaches, emission factors, and activity data. The largest $\mathrm{CH}_{4}$ contributions in IDF were from waste management (42\%), and the energy sector (31\%). ${ }^{15}$ Additionally, the residential and tertiary sector contributed to $13 \%$ of the total $\mathrm{CH}_{4}$ emission in IDF.

In 2012, a regional plan for climate, air and energy ${ }^{16}$ was approved for IDF. This plan envisages a $20 \%$ reduction of greenhouse gases for 2020, compared to the year 2005. Plans for reducing greenhouse gas emissions in Paris are more ambitious and expect to reach carbon neutrality by $2050 .{ }^{17}$ Understanding the $\mathrm{CH}_{4}$ emission trajectory in Paris, toward the completion of these ambitious plans, requires mapping and quantification of atmospheric $\mathrm{CH}_{4}$ and the attribution of the observed leaks to identified sources.

To achieve quantification and source attribution of methane emissions in the Paris area, we conducted repeated field measurement campaigns and monitoring activities, such as walking measurements and determining isotopic signatures of methane for the distinction of emission sources. The present work offers an approach to draw a baseline to assess the efficiency of future mitigation policies and actions. On the basis of these independent atmospheric measurements, we provide a sectoral perspective of $\mathrm{CH}_{4}$ emissions in Paris.

\section{MATERIALS AND METHODS}

The results presented in this paper were obtained from 17 surveys conducted between 07 September 2018 and 07 March 2019. The surveyed area includes Paris with its west and south suburbs (mostly Boulogne-Billancourt and Issy-les-Moulineaux). Cavity ring-down spectrometers (CRDS) and an AirCore sampler ${ }^{12,18-20}$ (Figure 1 and isotopic section) were installed into a vehicle equipped with a GPS device (NAVILOCK NL-602U). Vehicle-mounted instruments had air-inlets situated on the roof of the car. Walking measurements using a portable instrument were conducted to obtain detailed information about the source(s) of the observed enhancements. The AirCore sampler ${ }^{12,18,20}$ was used to determine the isotopic composition of observed enhancements and is described in the isotopic measurement section.

Instruments. Measurements during this study were made using CRDS analyzers manufactured by Picarro (Santa Clara, California) and a Los Gatos Research (LGR) analyzer (San Jose, California) model MGGA for more walking surveys. The LGR MGGA measures $\mathrm{CH}_{4}, \mathrm{CO}_{2}$ and $\mathrm{H}_{2} \mathrm{O}$. All the analyzers have an uncertainty below 1 ppb for $\mathrm{CH}_{4}$. (Detailed specifications are in the Supporting Information, SI.)

The base of our mobile setup is the CRDS G2201-i which was used for 16 of the surveys. This instrument measures $\mathrm{CO}_{2}$, $\delta^{13} \mathrm{CO}_{2}, \mathrm{CH}_{4}, \delta^{13} \mathrm{CH}_{4}$, and $\mathrm{H}_{2} \mathrm{O}$, with a gas flow of $\sim 160 \mathrm{sccm}$ and a frequency of $\sim 0.27 \mathrm{~Hz} . \delta^{13} \mathrm{CH}_{4}$ is reported using the international standard Vienna Pee Dee Belemnite (VPDB, ${ }^{13} \mathrm{C} /{ }^{12} \mathrm{C}$ vPDB $\left.=0.0112372\right)^{21}$ and $\mathrm{CH}_{4}$ using the WMO X2004A scale. Our CRDS G2201-i has a $\delta^{13} \mathrm{CH}_{4}$ precision of $\sim 3.5 \%$ o for ambient air $\mathrm{CH}_{4}$ mixing ratios, but as $\mathrm{CH}_{4}$ mixing ratios increase to $\sim 10 \mathrm{ppm}, \delta^{13} \mathrm{CH}_{4}$ precision improves to $0.7 \%$.

During 12 of the surveys, two other CRDS instruments, measuring $\mathrm{CH}_{4}$ and $\mathrm{H}_{2} \mathrm{O}$, were also used (G2401 or G2203). Details on which analyzer was used on any given day are shown in S1. To determine the influence of inlet height for measuring $\mathrm{CH}_{4}$ mixing ratios, two identical CRDS G2401 instruments were used during one of the surveys. One inlet was installed on the roof of the car $(\sim 170 \mathrm{~cm}$ above the ground) and the second on the upper skirt of the car $(\sim 50 \mathrm{~cm}$ above the ground). No significant difference was observed. Details of this test are presented in S2. All measurements are timecorrected to account for the delay ( 20 to $30 \mathrm{~s}$ ) induced by the travel time from the inlet (synflex $1 / 4^{\prime \prime}$ ) to the analyzers.

Between September 2018 and March 2019, a 3-point concentration and isotopic composition calibration was completed for CRDS G2201-i. The three calibration gases were made by different dilutions of pure $\mathrm{CH}_{4}$ and $\mathrm{CO}_{2}$ with ambient air and calibrated against primary standards. Calibration factors are hereafter applied. CRDS G2201-i calibration details are presented in S3. In addition, to check the $\mathrm{CH}_{4}$ and $\delta^{13} \mathrm{CH}_{4}$ measurement stability and the influence 


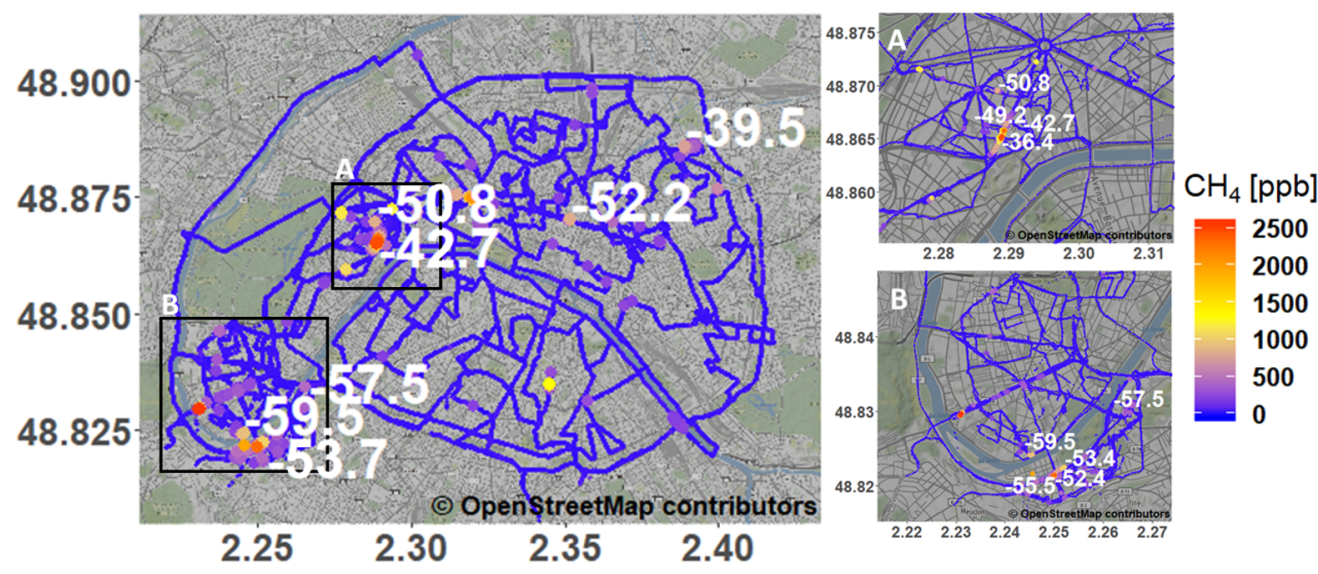

Figure 2. Paris $\mathrm{CH}_{4}$ enhancements above background with $\delta^{13} \mathrm{CH}_{4}$ signature (white numbers) determined for 11 leak indications selected by criteria: 1- $\sigma$ uncertainty less than $10 \%$ and a correlation coefficient $R^{2}>0.85$ from a Miller-Tans plot. Leak indications observed only once are also included. Left panel-whole measured area. To make the map more legible, part of leak indications in cluster areas A and B are treated as one leak indication with an averaged value. Right panel-zoom of cluster area A (top right) and B (bottom right). Base map provided by OpenStreetMap.

of powering on/off the analyzer, a known gas was measured for $20 \mathrm{~min}$ before and after 11 randomly selected surveys. In all cases, the analyzer was stable and there was no detectable influence observed from powering on/off the instrument. The LGR MGGA analyzer was also tested and calibration factors were applied.

Vehicle-Mounted Mobile Surveys and Leak Indications Analysis. Atmospheric background mixing ratios are calculated as 2 min running averages, and the enhancement threshold, to determine a leak indication of $\mathrm{CH}_{4}$, is defined as $>10 \%$ above background as in von Fisher et al. ${ }^{7}$ We assume leak indications are from the same source when their maximum enhancements are located no more than $150 \mathrm{~m}$ apart. Additionally, during a controlled release experiment, the spatial scale of $\mathrm{CH}_{4}$ enhancements were smaller than $160 \mathrm{~m}$ for leaks $\leq 40 \mathrm{~L} /$ min. ${ }^{7}$ Thus, $\mathrm{CH}_{4}$ enhancement with lengths $>160 \mathrm{~m}$ are not considered as leaks. In total 90 enhancements above background were retained.

High-Resolution $\delta^{13} \mathrm{CH}_{4}$ Signature Measurements. To obtain high precision in situ measurements of $\delta^{13} \mathrm{CH}_{4}$ for individual leak indications, our mobile setup was equipped with an AirCore sampler, which consists of a $50 \mathrm{~m}$ storage tube, a dryer (magnesium perchlorate), and valves (Figure 1). ${ }^{12,18-20}$ During surveys, air is continuously measured by the analyzer and simultaneously stored in the tube ("monitoring mode"). When a leak indication is detected and once the readings return to the background $\mathrm{CH}_{4}$ levels, the air within the storage tube is remeasured ("replay mode"). ${ }^{12,19,20}$ The uncertainty of isotopic signatures determined with the AirCore sampler depends on the instrument precision, the observed $\mathrm{CH}_{4}$ enhancement above background (higher enhancements lead to lower $\delta^{13} \mathrm{CH}_{4}$ uncertainties), and on the number of data points used for analysis. ${ }^{12}$ In the setup used in this study, the replay mode is equivalent to increasing the sampling frequency by a factor of 3 . Therefore, we used the AirCore to measure isotopic signatures only for significant $\mathrm{CH}_{4}$ enhancements above background. On the basis of all our observations, we chose to define a $\mathrm{CH}_{4}$ enhancement as "significant" if its maximum mixing ratio is greater than $500 \mathrm{ppb}$ above local background. In previous work, where the AirCore was a part of a mobile setup, the same threshold was also used. ${ }^{12,20}$ Local background values were calculated as the mean $\mathrm{CH}_{4}$ mixing ratio measured immediately before and after each leak indication in the replay mode.

In total, 28 leak indications from 17 different locations were found significant. Isotopic signatures were calculated using the Miller-Tans approach, ${ }^{19,23}$ offering comparison possibilities with previous studies. Fitting of the observations were calculated as a linear regression type II using the ordinary least-squares method, while data was grouped in $50 \mathrm{ppb}$ bins. As previous works ${ }^{19,24}$ showed ${ }^{13} \mathrm{CH}_{4}$ and $\mathrm{C}_{2} \mathrm{H}_{6}$ crosssensitivities in CRDS instruments, it is recommended to apply the $\mathrm{C}_{2} \mathrm{H}_{6}$ correction in the case of leak indications of thermogenic origin. However, in this study, the observed $\mathrm{CH}_{4}$ mixing ratios remained relatively low ( $\max$ of $2.7 \mathrm{ppm}$ above background), and the $\mathrm{C}_{2} \mathrm{H}_{6}$ mixing ratio was within instrumental noise. Here, we only report the isotopic $\delta^{13} \mathrm{CH}_{4}$ signature of leak indications where the Miller-Tans approach yields a $1-\sigma$ uncertainty less than $10 \%$ and with a correlation coefficient $R^{2}>0.85$. Twelve of the 28 AirCores samples fulfilled the criteria, with two AirCores measuring the same leak indication. Details of using the AirCore sampler and isotopic data processing are presented in S4.

Estimation of the Leak Indications' Emission Rate. While the source strength of each individual leak indication remains challenging to estimate, especially in urban areas, Weller et al., building on von Fischer et al., ${ }^{7}$ proposed an improved equation, using a statistical calibration model:

$$
\ln \left(\mathrm{M} \mathrm{CH}_{4}\right)=-0.988+0.817 \times \ln \left(\mathrm{CH}_{4} \text { emission rate }\right)
$$

$M$ is the maximum $\mathrm{CH}_{4}$ enhancement above the background of the leak indication [ppm], and emission rates are estimated in $\mathrm{L} / \mathrm{min}$. The method is developed and tested for point sources of methane situated at ground level in an urban environment. In previous studies, ${ }^{7,8}$ this approach was used only for leak indications from the natural gas distribution network, but it can also be extended to other sources. In our study, we have applied this equation to all leak indications in order to estimate the contribution of these different sources to city-scales $\mathrm{CH}_{4}$ emissions. The uncertainties of this equation are discussed in Weller et al. ${ }^{25}$ showing a slight overestimation for the small leak indications.

Mobile Surveys Protocol. Overall, among $720 \mathrm{~km}$ driven in the area of interest, 500 "unique" kilometers (driven without 
counting the revisits) were covered representing 30\% of the entire Paris road network. Surveys were conducted in different neighborhoods of the city during daytime hours, which included the coverage of major roads as well as part of the smaller roads. Locations where $\mathrm{CH}_{4}$ enhancements above background were observed to be lower than $500 \mathrm{ppb}$ were of low priority for a second survey. Initial surveys were used to identify areas with the largest number of $\mathrm{CH}_{4}$ enhancements above background, designated as "clusters". Two cluster areas were identified: (1) cluster area A, located in downtown Paris and (2) cluster area B, in the southwest suburbs. Five days of repeated surveys were focused on both clusters $A$ and $B$ (respectively 3 and 2 days). In total, clusters A and B represent respectively $10 \%(50 \mathrm{~km})$ and $20 \%(100 \mathrm{~km})$ of the unique kilometers (Figure 2). Primarily, during revisits of cluster areas $\mathrm{A}$ and $\mathrm{B}$, the measurements were concentrated at the locations where $\mathrm{CH}_{4}$ enhancements above background were previously observed. They were also extended to additional streets which were not previously investigated. In total, during the days that focused on cluster areas A and B, we covered every street at least twice.

Walking Measurements Using LGR MGGA. We collected additional measurements by foot using a LGR MGGA to find the exact position of the sources causing a significant $\mathrm{CH}_{4}$ enhancement above background when driving measurements were ambiguous. This protocol was implemented twice in cluster area $\mathrm{A}$, once in cluster area $\mathrm{B}$, and once in the central and northeast part of Paris (details in S5).

\section{RESULTS AND DISCUSSION}

Mapping of Methane Leak Indications in Paris. Figure 2 is a map of $\mathrm{CH}_{4}$ mixing ratio enhancements above background, along with the $\delta^{13} \mathrm{CH}_{4}$ signatures measured in Paris. Data represented in Figure 2 is from the CRDS G2201-i and the AirCore sampler, and includes streets that were only passed once. Zooms of cluster area A and B are included. Overall, methane enhancements above background are within a relatively low range (maximum 5\% of all measurements in the range 43 to $2700 \mathrm{ppb}$ ). Typically, crossing a leak indication took 12 to $20 \mathrm{~s}$. Overall 90 enhancements above threshold were observed, with $14 \%$ from area A, and $36 \%$ from area B. In cluster area $A$ and $B, 7$ and 17 single passed leak indications respectively were observed from streets passed twice. In the case of streets passed only once, single passed leak indications were observed 39 times outside of clusters. Some leak indications that were observed once may be due to vehicles using natural gas or to changing wind direction. Only considering the leak indications observed at least twice in the same location, 27 leak indications were detected in the Paris city. $22 \%$ of these leak indications are from cluster area A, and $56 \%$ from cluster area $B$, though these areas represent only $10 \%$ (area A) and 20\% (area B) of the unique $\mathrm{km}$ of the surveyed area.

Identification of Leak Indications' Origins. In this section, on the basis of measured isotopic values using the CRDS G2201-i with an AirCore sampler, and from additional walking observations using the LGR MGGA, we identify the origin of the leak indications shown in Figure 2.

Cluster Area $A$. The $\delta^{13} \mathrm{CH}_{4}$ isotopic signatures for the cluster area $A$ range between $-50.8 \pm 6.0 \%$ and $-36.4 \pm$ $2.6 \%$. The isotopic range for these leak indications are compatible with thermogenic sources, which are frequently connected to fugitive natural gas sources. During 2 days of walking measurements in cluster area $\mathrm{A}$, one $\mathrm{CH}_{4}$ enhancement was observed directly from a sewage ground cover, and another enhancement was from the ground cover of the natural gas network (Figures S9-S11). Additionally, $\mathrm{CH}_{4}$ enhancements were observed three times from ventilation grids connected to boiler rooms of buildings. To ensure the origin of an observed leak indication, using the portable LGR MGGA, measurements were taken directly above the venting grids and ground covers. With this approach, we could clearly distinguish that these leak indications were venting from the natural gas distribution network or from boiler rooms of certain buildings. On the basis of the location of detected peaks from venting grids and the location where isotopic samples were collected, we determined two isotopic source signatures: one equal to $-36.4 \pm 2.6 \%$ and another equal to $-39.5 \pm 5.0 \%$ o. To our knowledge, the latter source category (natural gas from boiler room venting) is not reported in previous studies that focus on urban environment. ${ }^{4-7}$

The highest enhancement measured directly from a ventilation grid of a boiler room was around $40 \mathrm{ppm}$ (S7). In buildings, boiler room ventilation systems are typically independent and separated from the buildings' ventilation of general air. Boilers are generally situated in the basement of a building. ${ }^{26}$ The discovery of high methane emissions suggests leaky installations of some furnaces, posing the presence of a safety hazard (although measured values are far from methane exploding zone) as well as a greenhouse gas emitter. As leaky furnace installations are a probable source of the methane from ventilation grids of boiler rooms, we will further call this category "furnaces". Walking measurements indicated a contribution of methane emissions from the city sewage network sector (i.e., pipes, covers), which in some previous studies was only briefly mentioned ${ }^{4,5}$ or not investigated at all. $6,7,10,22$

Leak indications identified by combining the determined isotopic signatures with the observed $\mathrm{CH}_{4}$ enhancements from walking measurements are presented in Figure 3. In cluster

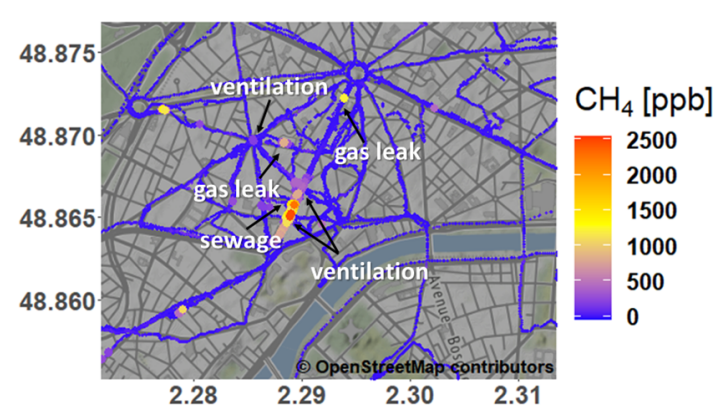

Figure 3. Type of $\mathrm{CH}_{4}$ sources detected in cluster area A. Source types are defined using isotopic compositions and detected $\mathrm{CH}_{4}$ emissions measured directly from ground covers (both sewage and the natural gas network) and boiler rooms of buildings venting through street-level grids (furnace category). Base map provided by OpenStreetMap.

area A, in total, 6 leak indications were detected. Three leak indications are from furnaces, two are from natural gas distribution network, and one is from the sewage network system. Using eq 1 , the total estimated emission, combining all leak indications observed twice is $21 \mathrm{~L} / \mathrm{min}$. However, if one considers all leak indications, including leak indications 
a)

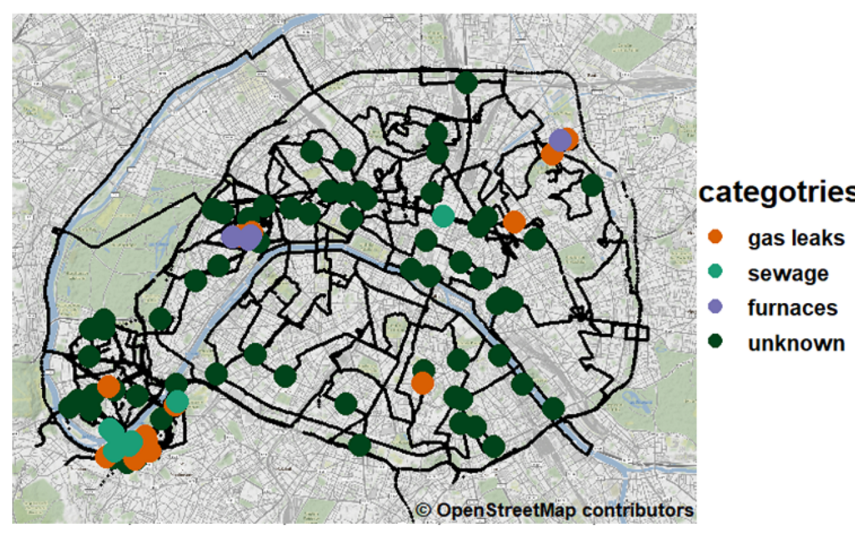

methane sources in Paris

b)

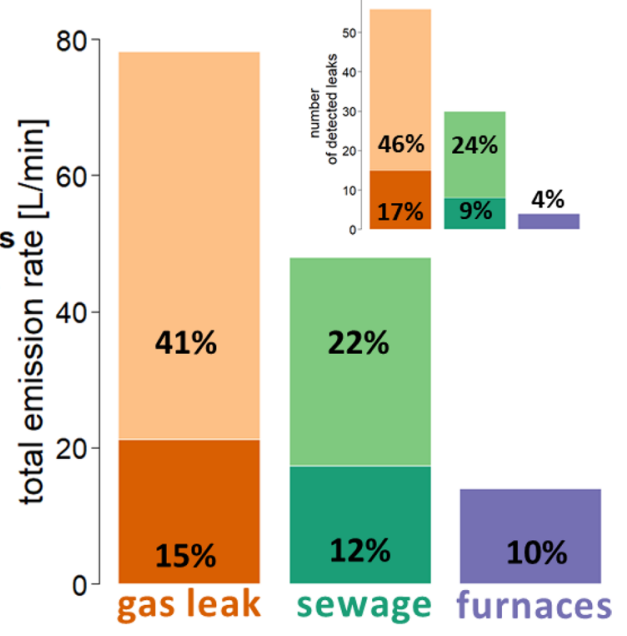

Figure 4. $\mathrm{CH}_{4}$ leak indication categories detected in the Paris area. (a) Map of the surveyed area with positions of the detected sources. (b) Distribution of the emission of the leak indication categories in the Paris area, inner figure: number of detected leaks. Paler colors represented unknown leaks attributed to gas leaks (orange) or sewage (green), based on the percent of defined leak indication. Base map provided by OpenStreetMap.

observed only once, the total emission in cluster area A reaches $39 \mathrm{~L} / \mathrm{min}$.

Cluster Area B. In cluster area B, 15 leak indications have been found. Here, 5 AirCore samples were collected. All isotopic signatures associated with these leak indications fall within the range of $-59.5 \pm 8.1 \%$ to $-52.4 \pm 3.1 \%$. This range of values suggest more a microbial origin of the emissions than a thermogenic one. As cluster area $\mathrm{B}$ has no landfills and because the IDF region uses natural gas of thermogenic origin (personal communication, ${ }^{14}$ ), these leak indications are assigned to sewage emissions. Walking measurements were done during one measurement day (02/ 27/2019) in cluster area $\mathrm{B}$, and indicated that $\mathrm{CH}_{4}$ enhancements were discharging from sewage ground covers and natural gas ground covers. However, leak indication from natural gas ground covers were too small to determine their isotopic signature using AirCore sampler. In cluster area B, 9 leak indications are from the natural gas distribution network and 6 leak indications are from the sewage network. The total emission rate for the identified leak indications is $23 \mathrm{~L} / \mathrm{min}$. In cluster area $\mathrm{B}$, emissions from furnaces were not observed. The total emission rate in cluster area $\mathrm{B}$, adding leak indications observed only once, reaches $50 \mathrm{~L} / \mathrm{min}$.

A small isolated $\mathrm{CH}_{4}$ leak indication (238 ppb above local background), that was observed twice in the central part of the city of Paris, had a $\delta^{13} \mathrm{CH}_{4}$ isotopic signature of $-52.2 \pm$ $8.1 \%$ o. This signature is compatible to isotopic signatures observed in cluster area B, where sewage covers were directly measured and to the WWTP in the IDF region $(-51.9 \pm$ $0.2 \% o$ and $-55.3 \pm 0.1 \% 0) .{ }^{14}$ Accordingly, the leak indication's origin is attributed to sewage. Another isolated leak indication, observed in the northeast part of Paris, had an isotopic signature of $-39.5 \pm 5.0 \%$ which is comparable to thermogenic sources. Outside of cluster areas A and B, 6 leak indications were observed twice. Of these six, one leak indication was determined by walking measurements, two others using isotopic signatures, and for the remaining three leak indications, neither isotopic signature nor walking measurements were possible to conduct. Outside of the cluster areas $\mathrm{A}$ and $\mathrm{B}$, including single observations, the total $\mathrm{CH}_{4}$ emission rate is equal to $51 \mathrm{~L} / \mathrm{min}$.

Synthesis. Overall, 90 leaks were detected and an origin of 27 leak indications was identified. Out of the latter 27, 15 are attributed to the natural gas network, 8 to sewage, and 4 to furnaces. The 63 remaining leak indications could not be attributed using isotopes or walking measurements (Figure $4 a)$. From the road, furnaces and natural gas networks are not distinguishable from each other. Thus, $66 \%$ of leak indications in Paris come from natural gas leaks and 34\% from sewage network. This distribution of source categories is propagated to the 63 leaks of unknown origin and 41 additional leaks are considered as coming from gas leaks and 22 as sewage network leaks (Figure 4b). Isotopic signatures and their source locations are presented in Table S4, and pictures of examples from $\mathrm{CH}_{4}$ sources in cluster areas $\mathrm{A}$ and $\mathrm{B}$ are presented in $\mathrm{S} 7$.

Using the method from Weller et al. ${ }^{8}$ (eq 1), we calculated the emission rate for the 90 leak indications determined in Paris. For the 15 determined natural gas distribution leak indications, the mean estimated emission rate is equal to $1.4 \mathrm{~L} /$ min (range $0.5-3.87 \mathrm{~L} / \mathrm{min}$ ) for individual leak indication. These natural gas leaks are categorized as small leaks $(<6 \mathrm{~L} /$ min), according to the categorization proposed by von Fischer et al. ${ }^{7}$ For the sewage sector, the mean estimated emission rate for an individual leak indication is equal to $2.2 \mathrm{~L} / \mathrm{min}(0.7$ to $6.5 \mathrm{~L} / \mathrm{min})$. In this case, 7 leak indications are within the small category and one leak indication is within the medium category. For the furnace sector, the mean emission rate for an individual leak indication is equal to $3.5 \mathrm{~L} / \mathrm{min}(0.7$ to $5.9 \mathrm{~L} /$ $\mathrm{min})$. The remaining 63 leak indications have a mean estimated emission rate equal to $1.4 \mathrm{~L} / \mathrm{min}(0.5-10.5 \mathrm{~L} /$ min), where only one is categorized as a medium, which reached $10.5 \mathrm{~L} / \mathrm{min}$. Thus, in this group, the emission rates for individual leaks are skewed for lower emissions, with median values equal to $0.8 \mathrm{~L} / \mathrm{min}$.

Overall, for 500 unique $\mathrm{km}$, the accumulated emission rate is equal to $140 \mathrm{~L} / \mathrm{min}$, where the gas sector contributes $56 \%$ under our attribution assumption (Figure $4 \mathrm{~b}$ ). The sewage sector and furnace category, respectively, contribute to $34 \%$ and $10 \%$ of the accumulated rate. After upscaling this value to 
all kilometers of road in Paris and suburbs, the accumulated $\mathrm{CH}_{4}$ emission rate of sources detectable from the ground is estimated to be equal to $500 \mathrm{~L} / \mathrm{min}(190 \mathrm{t} / \mathrm{yr})$. Such a simple extrapolation assumes a reasonable homogeneity of the leak distribution regarding the fraction of the total kilometers sampled during our surveys. Thus, in Paris at the street-level, $54 \%$ of total $\mathrm{CH}_{4}$ emissions come from leaks in natural gas distribution network, $34 \%$ from leaks in sewage network and $10 \%$ from furnaces leaking emissions. Looking only for the leaks in the natural gas distribution network, the natural gas leak indication rate (gas leak indications/unique kilometers) is equal to $0.11 \mathrm{~km}^{-1}$.

However, it may be considered a lower bound estimate as additional sources may not be detectable from the ground or with our set up. Indeed, we do not report mobile $\mathrm{CH}_{4}$ sources from road transport. A fraction of the bus fleet in Paris uses natural gas and biogas as fuel, which can cause additional emission of $\mathrm{CH}_{4} \cdot{ }^{27-29}$ According to the AIRPARIF inventory, road transport contributed to $3 \%$ of $\mathrm{CH}_{4}$ emissions in Paris for the year 2015. ${ }^{15}$ In our study, we attribute $\mathrm{CH}_{4}$ emission to road transport if the detected leak indication does not occur during the second passing of the same street in a short time. One leak indication is associated with emissions from road transport and has been excluded from the analysis (Section S9). Addressing a road transport category would necessitate specifically designed campaigns.

More diffused $\mathrm{CH}_{4}$ sources, like emissions from the Seine river could be missing. However, during our study we did not observe any $\mathrm{CH}_{4}$ enhancement along the Seine, what is in the line with previous, focused on Seine greenhouse gases emissions study. ${ }^{30,31}$ Finally, the roof-top venting of buildings could also be a source of methane that we can hardly track with our setup.

Outlook on Improvements to the Measurement Method. We see three main ways to improve our method: better instrumentation, additional tracer, and multiples revisits.

Indeed, we were able to obtain $\delta^{13} \mathrm{CH}_{4}$ signatures through mobile measurements of the combined G2201-i analyzer and AirCore sampler only if a $\mathrm{CH}_{4}$ enhancement above background was at least $500 \mathrm{ppb}$. It constitutes a bias toward large sources, possibly ignoring potentially numerous small or more diffused sources. Using another instrument with higher precision would decrease the threshold for the observed $\mathrm{CH}_{4}$ enhancements above background. This would allow for the isotopic composition measurement of smaller leak indications and thus allow the detection of more leaks.

Additionally, measurements of $\delta \mathrm{D}$ and radiocarbon $\left({ }^{14} \mathrm{C}\right)$ could provide complementary information about emission sources. Continuous $\delta \mathrm{D}$ observations, based on CRDS technology, have only started to be used. ${ }^{32}$ For radiocarbon, however, with current techniques, leak indications should be measured through canister collections instead of through continuous measurements, which can cause some difficulties in the flow of urban traffic. ${ }^{4,33-35}$

Measurements of ethane to methane ratios can also help to distinguish thermogenic from microbial sources since ethane is not observed in microbial sources. ${ }^{6,10,20}$ These measurements can be included during mobile surveys ${ }^{20}$ or they can be stationary. ${ }^{36,37}$ The measurements of ethane to methane ratios can be useful to determine the possibility of migrating methane from the natural gas distribution network to the sewage network, as seen in McKain et al. ${ }^{23}$ Lastly, CO observations can identify events of incomplete combustion, which can differentiate emissions from bus exhaust or, what is observed in Paris, from furnaces. Taking into account the efficiency of identifying $\mathrm{CH}_{4}$ combustion sources with $\mathrm{CO}$ measurements, it is recommended to systematically measure $\mathrm{CO}$ during future urban quantification investigations.

Finally, the systematic repetition of measurements would allow for an observation of seasonal variations of $\mathrm{CH}_{4}$ emissions in an urban structure. Also, measuring both in winter and summer can separate gas leak emissions from the heating system emissions and leaks in natural gas distribution network, as gas leaks have little seasonal variation. $3,5,34$ However, in this case, maintenance, repairs, and replacement plans of gas pipeline infrastructure should be documented to inform emission measurement investigations. In our work, we analyze leak indications, which were systematically observed between September 2018 and March 2019. Systematic repetitions could help distinguishing stationary methane sources (e.g., natural gas network or sewage system) from moving sources (e.g., car exhaust).

Comparison to Previous Studies about Paris Methane Emissions. Inventories. In IDF region, the total $\mathrm{CH}_{4}$ emission in 2015 from the AIRPARIF inventory ${ }^{15}$ was equal to $30 \mathrm{kt}$, with the largest emission coming from the solid waste management sector (47\%). ${ }^{15}$ However, AIRPARIF inventory does not take sewage emissions into consideration. Emissions from furnaces are part of the tertiary and residential sector, but considering that these leak indications were only found for a limited number of walking passes, their emission rates are not representative of the total emission from furnaces, and even less for the whole tertiary and residential sector. For our study, the sector of interest is thus "energy sector", which emitted 9.3 $\mathrm{kt} / \mathrm{yr}$ in IDF region in 2015, ${ }^{15}$ according to AIRPARIF. Within the energy sector, gas leaks represent $87 \%(8.1 \mathrm{kt} / \mathrm{yr})$ of annual emissions. ${ }^{38}$ This estimate relates to the downscaled national length of distribution network and real natural gas consumption in IDF.

In Paris, the natural gas distribution network has a length of about $2000 \mathrm{~km}$ and serves almost all streets and more than 40000 buildings. ${ }^{39,40}$ Annually, $40 \mathrm{~km}$ of the pipelines are repaired in Paris. ${ }^{40,41}$ More detailed information, such as age and type of the pipelines or the location of the repair works are not freely available for Paris. This lack of information makes it difficult to assess the leak rate based on actual conditions of the natural gas network.

From the 2010 AIRPARIF inventory map, ${ }^{14,38}$ the largest emission from oil and gas distribution is shown in the northern part of Paris, especially along the right bank of the Seine River, which is not in agreement with our study. The discrepancy between the inventory and our study may be influenced by the time gap ( 10 years ago) between the two investigations and possibly from repairs or pipeline replacements of less leak prone pipe material made in this area over this time. However, on the basis of the AIRPARIF inventory, ${ }^{38}$ (i) gas emissions are broadly distributed spatially and larger $\mathrm{CH}_{4}$ emission was determined in cluster $\mathrm{A}$, which is consistent with our work, and (ii) $\mathrm{CH}_{4}$ emissions exist in cluster $\mathrm{B}$, though less than in cluster A, which may imply the lack of accounting for sewage emissions in the inventory.

In 2015, the AIRPARIF regional inventory emissions from the energy sector, downscaled by the population of Paris, reached $1.6 \mathrm{kt} / \mathrm{y}$ for Paris city. Another inventory, using national emissions reported to the UNFCCC from fossil fuel exploitation, ${ }^{42}$ reports an annual 2016 emission for the grid cell 
that contains most of Paris of $1.25 \mathrm{kt} / \mathrm{yr}$, which is in agreement with AIRPARIF.

In our study, we upscaled our emission rates for the energy sector to the road total length of the city, resulting in an emission of $106 \mathrm{t} / \mathrm{yr}$, which is 15 times less than in the downscaled AIRPARIF estimate. It does not seem possible to directly compare the gas distribution network $\mathrm{CH}_{4}$ emission estimates of our study with AIRPARIF inventory, given (i) the source aggregation in the inventory (i.e., gas distribution network, end use, and road transport using natural gas as a fuel), (ii) the downscaling by population in the inventory instead of using absolute information regarding pipe length and material, and (iii) the possibly underestimation of our estimate as noted previously.

Mobile Measurements. A previous study, also using mobile measurements, surveyed about $1000 \mathrm{~km}$ of Paris and the south/southeast suburbs between December 2013 and December 2015. ${ }^{14}$ This study focused on different methane sources like gas storage facilities, but the methodology of the city surveys was not fully described. Also, information about repeated street measurements is not provided. ${ }^{14}$ That study detected 40 local enhancements above background, where the maximum leak indication was $3500 \mathrm{ppb}$.

Additionally, this former study observed two enhancements $>3500 \mathrm{ppb}$ located in a northern part of Paris. Isotopic measurements using a CRDS analyzer yielded values of -39.1 $\pm 2 \%$ and $-41.8 \pm 2 \% 0^{14}$ Our study detected a leak indication close to the area of their second value, which we measured with an isotopic composition equal to $-39.5 \pm$ $5.0 \%$. In this residential area, both results consistently indicate, for two different periods, a thermogenic origin of the $\mathrm{CH}_{4}$ emission.

Comparison to Other Cities. Several U.S. cities received attention regarding their methane emissions. For Indianapolis, Lamb et al. ${ }^{6}$ identified leaks from the natural gas pipeline network as the main source of $\mathrm{CH}_{4}$ emissions (43\%, leaks rate 0.08 leak $/ \mathrm{km}){ }^{6}$ According to McKain et al., ${ }^{10}$ depending on the season, the natural gas sector of Boston, contributes 60$100 \%$ of the total emission, ${ }^{10}$ and had a mean leak rate of 0.74 leak $/ \mathrm{km}^{6}$. In Indianapolis, $41 \%$ of the pipeline system consists of cathodically protected steel and $51 \%$ of the main pipelines are plastic, ${ }^{6}$ while Boston's pipelines are mostly composed of unprotected steel and cast iron. ${ }^{10}$ Also, von Fischer et al. ${ }^{7}$ confirmed that the number of gas leaks in U.S. cities, with older corrosion-prone pipeline network (Boston, New York, Staten Island and Syracuse), is higher than for cities with a higher proportion of plastic or protected steel low-pressure distribution systems (Burlington and Indianapolis). In the case of the study made by von Fischer et al., ${ }^{7}$ leak rates vary from 0.004 leaks $/ \mathrm{km}$ (Indianapolis) to 0.63 leaks $/ \mathrm{km}$ (Staten Island). ${ }^{7}$ Depending on the U.S. city, the small gas leak indications contribute to $83 \%-100 \%$ of total detected gas leak indications. However, gas leak indications categorized as medium $(0-17 \%)$ and large $(0-2 \%)$ are responsible for the majority of the emissions. In our study, Paris leak indications from the natural gas network resulted in a leak rate of 0.11 leak indications per unique driven $\mathrm{km}$ and are categorized as small leaks. Therefore, Paris is in the middle to low range compared to U.S cities, according to von Fischer et al. ${ }^{7}$ leak size categories. $^{7}$

In our study, only two leak indications exceeded $2.5 \mathrm{ppm}$ above background over 500 unique $\mathrm{km}$ driven in Paris, where one is from sewage and the second is from an unknown source.
Mobile measurements conducted in 2014 in London (U.K.) found 11 gas leaks with enhancement larger than $2.5 \mathrm{ppm}$ above background over $260 \mathrm{~km}^{5}$, which suggests that London is a city with larger $\mathrm{CH}_{4}$ emissions than Paris. The London results $^{5}$ allowed for the verification of the National Atmospheric Emission Inventory (NAEI) of $\mathrm{CH}_{4}$ reflecting a significant discrepancy of natural gas leak locations between the inventory and the mobile measurements. There, the $\mathrm{CH}_{4}$ emissions from sewage works determined by inventory and mobile measurements were in good agreement, while for natural gas leaks, observed leak indications were incorrectly spatially disaggregated, and likely underestimated in the NAEI inventory. ${ }^{5}$ In contrast to the London study, the discrepancy found between inventory and the present work appears to be likely caused by an absence of sewage sector estimations in the AIRPARIF inventory, and also by possible repairs works of the natural gas distribution network in the measured area. ${ }^{38,43}$

Studies in London ${ }^{5}$ and Los Angeles ${ }^{4}$ found contributions from the sewage sector to urban $\mathrm{CH}_{4}$ emission. In both studies, ${ }^{4,5} \mathrm{CH}_{4}$ contributions from the sewage sector were observed from WWTP, which can be linked to the type of the collecting system (open versus closed system). Moreover, Zazzeri et al. ${ }^{5}$ reported the possibility of $\mathrm{CH}_{4}$ emission from toilet/sewage vent. No WWTP is located in the city of Paris, but $\mathrm{CH}_{4}$ leak indications were observed from ground covers of the sewage network. Their isotopic signatures are linked to biogenic sources.

Implications for Policymakers. Actions to reduce greenhouse gas emissions in IDF region and Paris already exist or are planned both on the regional and city scales. ${ }^{16,17}$ These plans consider all greenhouse gases, but mostly focus on decreasing $\mathrm{CO}_{2}$ emissions. Mitigation of $\mathrm{CH}_{4}$ emissions is not discussed in detail.

Our findings provide evidence of existing methane leaks that can be reduced, offering possibilities to mitigate greenhouse gas emissions in the Paris area. However, additional measurements are required to improve the data coverage of the city more extensively and to precisely identify the origin of each source. Also, the nature and magnitude of furnace emission should be identified and quantified to be mitigated. Buses which use natural gas and biogas as fuel instead of petrol and diesel are already used in Paris and will be more frequent in the future, being a possible increasing source of methane to watch closely.

Additionally, Paris plans to replace natural gas in the distribution network with biogas partially produced locally. ${ }^{17,39}$ This should be monitored as well, being another potential source of $\mathrm{CH}_{4}$ in Paris. The method presented in this paper can be reproduced at multiyear intervals to assess the changes in the structure of $\mathrm{CH}_{4}$ emissions in Paris, and to determine the impact of the mitigation actions for $\mathrm{CH}_{4}$ emissions.

\section{ASSOCIATED CONTENT}

\section{St Supporting Information}

The Supporting Information is available free of charge at https://pubs.acs.org/doi/10.1021/acs.est.1c00859.

S1, Analyzers used during vehicle mounted surveys; S2, inlet position; S3, calibration procedure; S4, isotopes measurements; S5, walking measurements with LGR MGGA; S6, maps of observed enhancement above background; S7, source type determined by mobile car measurements and walking measurements; S8, daily 
measurements over time; and S9, excluding road transport (PDF)

\section{AUTHOR INFORMATION}

\section{Corresponding Author}

Sara M. Defratyka - Laboratoire des Sciences du Climat et de l'Environnement (LSCE-IPSL) CEA-CNRS-UVSQ

Université Paris Saclay, Gif-sur-Yvette 91190, France;

๑ orcid.org/0000-0002-9488-4518;

Email: sara.defratyka@lsce.ipsl.fr

\section{Authors}

Jean-Daniel Paris - Laboratoire des Sciences du Climat et de l'Environnement (LSCE-IPSL) CEA-CNRS-UVSQ Université Paris Saclay, Gif-sur-Yvette 91190, France

Camille Yver-Kwok - Laboratoire des Sciences du Climat et de l'Environnement (LSCE-IPSL) CEA-CNRS-UVSQ Université Paris Saclay, Gif-sur-Yvette 91190, France

Julianne M. Fernandez - Royal Holloway University of London, Egham TW20 OEX, United Kingdom

Piotr Korben - Heidelberg University, Institute of Environmental Physics, Heidelberg D-69120, Germany

Philippe Bousquet - Laboratoire des Sciences du Climat et de l'Environnement (LSCE-IPSL) CEA-CNRS-UVSQ

Université Paris Saclay, Gif-sur-Yvette 91190, France

Complete contact information is available at:

https://pubs.acs.org/10.1021/acs.est.1c00859

\section{Author Contributions}

The manuscript was written through contributions of all authors. All authors have given approval to the final version of the manuscript.

\section{Funding}

This work was partly funded under European Union's Horizon 2020 research and innovation program under the Marie Sklodowska-Curie grant agreement No 722479. This work was partly funded under the Climate and Clean Air Coalition (CCAC) Oil and Gas Methane Science Studies (MSS), hosted by the United Nations Environment Programme. Funding was provided by the Environmental Defense Fund, Oil and Gas Climate Initiative, European Commission, and CCAC.

\section{Notes}

The authors declare no competing financial interest.

\section{ACKNOWLEDGMENTS}

This project has received funding from the European Union's Horizon 2020 research and innovation programme under the Marie Sklodowska-Curie grant agreement No 722479. This work was funded under the Climate and Clean Air Coalition (CCAC) Oil and Gas Methane Science Studies (MSS), hosted by the United Nations Environment Programme. Funding was provided by the Environmental Defense Fund, Oil and Gas Climate Initiative, European Commission, and CCAC. The authors are grateful to P.Y. Quehe for his help with driving and collecting measurements in the field. We thank AIRPARIF and in particular O. Perrussel for access to the AIRPARIF 2018 methane emissions inventory.

\section{ABBREVIATIONS USED}

$\begin{array}{ll}{ }^{14} \mathrm{C} & \text { radiocarbon } \\ \text { AIRPARIF } & \text { Air Quality network of Ile-de-France } \\ \mathrm{CH}_{4} & \text { methane }\end{array}$

CRDS cavity ring-down spectrometer analyzer

IDF region Ile-de-France region

LGR MGGA Los Gatos Research MGGA portable analyzer

NAEI National Atmospheric Emission Inventory

VPDB Vienna Pee Dee Belemnite

WWTP wastewater treatment plant

\section{REFERENCES}

(1) Global Carbon Project; https://www.globalcarbonproject.org/ methanebudget/index.htm (accessed Dec 5, 2019).

(2) Saunois, M.; Bousquet, P.; Poulter, B.; Peregon, A.; Ciais, P.; Canadell, J. G.; Dlugokencky, E. J.; Etiope, G.; Bastviken, D.; Houweling, S.; Janssens-Maenhout, G.; Tubiello, F. N.; Castaldi, S.; Jackson, R. B.; Alexe, M.; Arora, V. K.; Beerling, D. J.; Bergamaschi, P.; Blake, D. R.; Brailsford, G.; Brovkin, V.; Bruhwiler, L.; Crevoisier, C.; Crill, P.; Covey, K.; Curry, C.; Frankenberg, C.; Gedney, N.; Höglund-Isaksson, L.; Ishizawa, M.; Ito, A.; Joos, F.; Kim, H.-S.; Kleinen, T.; Krummel, P.; Lamarque, J.-F.; Langenfelds, R.; Locatelli, R.; Machida, T.; Maksyutov, S.; McDonald, K. C.; Marshall, J.; Melton, J. R.; Morino, I.; Naik, V.; O’Doherty, S.; Parmentier, F. W.; Patra, P. K.; Peng, C.; Peng, S.; Peters, G. P.; Pison, I.; Prigent, C.; Prinn, R.; Ramonet, M.; Riley, W. J.; Saito, M.; Santini, M.; Schroeder, R.; Simpson, I. J.; Spahni, R.; Steele, P.; Takizawa, A.; Thornton, B. F.; Tian, H.; Tohjima, Y.; Viovy, N.; Voulgarakis, A.; van Weele, M.; van der Werf, G. R.; Weiss, R.; Wiedinmyer, C.; Wilton, D. J.; Wiltshire, A.; Worthy, D.; Wunch, D.; Xu, X.; Yoshida, Y.; Zhang, B.; Zhang, Z.; Zhu, Q. The Global Methane Budget 20002012. Earth System Science Data 2016, 8 (2), 697-751.

(3) Gioli, B.; Toscano, P.; Lugato, E.; Matese, A.; Miglietta, F.; Zaldei, A.; Vaccari, F. P. Methane and Carbon Dioxide Fluxes and Source Partitioning in Urban Areas: The Case Study of Florence, Italy. Environ. Pollut. 2012, 164, 125-131.

(4) Townsend-Small, A.; Tyler, S. C.; Pataki, D. E.; Xu, X.; Christensen, L. E. Isotopic Measurements of Atmospheric Methane in Los Angeles, California, USA: Influence of "Fugitive" Fossil Fuel Emissions. J. Geophys. Res.: Atmos. 2012, 117 (D7), n/a.

(5) Zazzeri, G.; Lowry, D.; Fisher, R. E.; France, J. L.; Lanoisellé, M.; Grimmond, C. S. B.; Nisbet, E. G. Evaluating Methane Inventories by Isotopic Analysis in the London Region. Sci. Reports 2017, 7 (4854). DOI: $10.1038 / \mathrm{s} 41598-017-04802-6$.

(6) Lamb, B. K.; Cambaliza, M. O. L.; Davis, K. J.; Edburg, S. L.; Ferrara, T. W.; Floerchinger, C.; Heimburger, A. M. F.; Herndon, S.; Lauvaux, T.; Lavoie, T.; Lyon, D. R.; Miles, N.; Prasad, K. R.; Richardson, S.; Roscioli, J. R.; Salmon, O. E.; Shepson, P. B.; Stirm, B. H.; Whetstone, J. Direct and Indirect Measurements and Modeling of Methane Emissions in Indianapolis, Indiana. Environ. Sci. Technol. 2016, 50 (16), 8910-8917.

(7) von Fischer, J. C.; Cooley, D.; Chamberlain, S.; Gaylord, A.; Griebenow, C. J.; Hamburg, S. P.; Salo, J.; Schumacher, R.; Theobald, D.; Ham, J. Rapid, Vehicle-Based Identification of Location and Magnitude of Urban Natural Gas Pipeline Leaks. Environ. Sci. Technol. 2017, 51 (7), 4091-4099.

(8) Weller, Z. D.; Yang, D. K.; von Fischer, J. C. An Open Source Algorithm to Detect Natural Gas Leaks from Mobile Methane Survey Data. PLoS One 2019, 14 (2), No. e0212287.

(9) Schwietzke, S.; Sherwood, O. A.; Bruhwiler, L. M. P.; Miller, J. B.; Etiope, G.; Dlugokencky, E. J.; Michel, S. E.; Arling, V. A.; Vaughn, B. H.; White, J. W. C.; Tans, P. P. Upward Revision of Global Fossil Fuel Methane Emissions Based on Isotope Database. Nature 2016, 538 (7623), 88-91.

(10) McKain, K.; Down, A.; Raciti, S. M.; Budney, J.; Hutyra, L. R.; Floerchinger, C.; Herndon, S. C.; Nehrkorn, T.; Zahniser, M. S.; Jackson, R. B.; Phillips, N.; Wofsy, S. C. Methane Emissions from Natural Gas Infrastructure and Use in the Urban Region of Boston, Massachusetts. Proc. Natl. Acad. Sci. U. S. A. 2015, 112 (7), 19411946.

(11) Sherwood, O. A.; Schwietzke, S.; Arling, V. A.; Etiope, G. Global Inventory of Gas Geochemistry Data from Fossil Fuel, 
Microbial and Burning Sources, Version 2017. Earth Syst. Sci. Data 2017, 9 (2), 639-656.

(12) Hoheisel, A.; Yeman, C.; Dinger, F.; Eckhardt, H.; Schmidt, M. An Improved Method for Mobile Characterisation of $\delta^{13} \mathrm{CH}_{4}$ Source Signatures and Its Application in Germany. Atmos. Meas. Tech. 2019, 12 (2), 1123-1139.

(13) Lowry, D.; Holmes, C. W.; Rata, N. D.; O’Brien, P.; Nisbet, E. G. London Methane Emissions: Use of Diurnal Changes in Concentration and $\delta^{13} \mathrm{C}$ to Identify Urban Sources and Verify Inventories. Journal of Geophysical Research: Atmospheres 2001, 106 (D7), 7427-7448.

(14) Xueref-Remy, I.; Zazzeri, G.; Bréon, F. M.; Vogel, F.; Ciais, P.; Lowry, D.; Nisbet, E. G. Anthropogenic Methane Plume Detection from Point Sources in the Paris Megacity Area and Characterization of Their $\delta^{13} \mathrm{C}$ Signature. Atmos. Environ. 2020, 222, 117055.

(15) Ile-de-France Inventories for a Year 2015. AIRPARIF 2018; Personal communication.

(16) SRCAE. Schéma Régional Du Climat, de l'Air et de l'Energie de l'Île-de-France. Arrêté prefectoral No 2012272-001, 2012. http:// www.srcae-idf.fr/ (accessed March 19, 2019).

(17) Le Plan Climat Air Energie: une stratégie globale pour le climat à Paris. 2018. https://www.apc-paris.com/plan-climat (accessed Sep 7, 2019).

(18) Karion, A.; Sweeney, C.; Tans, P.; Newberger, T. AirCore: An Innovative Atmospheric Sampling System. J. Atmos. Oceanic Technol. 2010, 27 (11), 1839-1853.

(19) Rella, C. W.; Hoffnagle, J.; He, Y.; Tajima, S. Local- and Regional-Scale Measurements of $\mathrm{CH}_{4}, \delta^{13} \mathrm{CH}_{4}$, and $\mathrm{C}_{2} \mathrm{H}_{6}$ in the Uintah Basin Using a Mobile Stable Isotope Analyzer. Atmos. Meas. Tech. 2015, 8 (10), 4539-4559.

(20) Lopez, M.; Sherwood, O. A.; Dlugokencky, E. J.; Kessler, R.; Giroux, L.; Worthy, D. E. J. Isotopic Signatures of Anthropogenic $\mathrm{CH}_{4}$ Sources in Alberta, Canada. Atmos. Environ. 2017, 164, 280288.

(21) Craig, H. Isotopic Standards for Carbon and Oxygen and Correction Factors for Mass-Spectrometric Analysis of Carbon Dioxide. Geochim. Cosmochim. Acta 1957, 12, 133-149.

(22) Jackson, R. B.; Down, A.; Phillips, N. G.; Ackley, R. C.; Cook, C. W.; Plata, D. L.; Zhao, K. Natural Gas Pipeline Leaks Across Washington, DC. Environ. Sci. Technol. 2014, 48 (3), 2051-2058.

(23) Miller, J. B.; Tans, P. P. Calculating Isotopic Fractionation from Atmospheric Measurements at Various Scales. Tellus, Ser. B 2003, 55 (2), 207-214.

(24) Assan, S.; Baudic, A.; Guemri, A.; Ciais, P.; Gros, V.; Vogel, F. R. Characterization of Interferences to in Situ Observations of $\delta^{13} \mathrm{CH}_{4}$ and $\mathrm{C}_{2} \mathrm{H}_{6}$ When Using a Cavity Ring-down Spectrometer at Industrial Sites. Atmos. Meas. Tech. 2017, 10 (6), 2077-2091.

(25) Weller, Z. D.; Roscioli, J. R.; Daube, W. C.; Lamb, B. K.; Ferrara, T. W.; Brewer, P. E.; von Fischer, J. C. Vehicle-Based Methane Surveys for Finding Natural Gas Leaks and Estimating Their Size: Validation and Uncertainty. Environ. Sci. Technol. 2018, 52, $11922-11930$.

(26) Aménagement d'une chaufferie en sous-sol https://cegibat.grdf. $\mathrm{fr} /$ reglementation-gaz/amenagement-chaufferie-sous-sol (accessed April 22, 2020).

(27) Hesterberg, T. W.; Lapin, C. A.; Bunn, W. B. A Comparison of Emissions from Vehicles Fueled with Diesel or Compressed Natural Gas. Environ. Sci. Technol. 2008, 42 (17), 6437-6445.

(28) Clark, N. N.; Johnson, D. R.; McKain, D. L.; Wayne, W. S.; Li, H.; Rudek, J.; Mongold, R. A.; Sandoval, C.; Covington, A. N.; Hailer, J. T. Future Methane Emissions from the Heavy-Duty Natural Gas Transportation Sector for Stasis, High, Medium, and Low Scenarios in 2035. J. Air Waste Manage. Assoc. 2017, 67 (12), 1328-1341.

(29) The Role of Natural Gas and Biomethane in the Transport Sector; ED61479(1); Ricardo Energy \& Environment, 2016; https:// www.transportenvironment.org/publications/natural-gas-vehicles\%E2\%80\%93-road-nowhere.

(30) Garnier, J.; Vilain, G.; Silvestre, M.; Billen, G.; Jehanno, S.; Poirier, D.; Martinez, A.; Decuq, C.; Cellier, P.; Abril, G. Budget of
Methane Emissions from Soils, Livestock and the River Network at the Regional Scale of the Seine Basin (France). Biogeochemistry 2013, 116, 199-214.

(31) Marescaux, A.; Thieu, V.; Garnier, J. Carbon Dioxide, Methane and Nitrous Oxide Emissions from the Human-Impacted Seine Watershed in France. Sci. Total Environ. 2018, 643, 247-259.

(32) Isotopic Measurements. Aerodyne Research, Inc. http://www. aerodyne.com/application/isotopic-measurements (accessed Jun 6, 2019).

(33) Nakagawa, F.; Tsunogai, U.; Komatsu, D. D.; Yamada, K.; Yoshida, N.; Moriizumi, J.; Nagamine, K.; Iida, T.; Ikebe, Y. Automobile Exhaust as a Source of ${ }^{13} \mathrm{C}$ - and D-Enriched Atmospheric Methane in Urban Areas. Org. Geochem. 2005, 36 (5), 727-738.

(34) Moriizumi, J.; Nagamine, K.; Iida, T.; Ikebe, Y. Carbon isotopic analysis of atmospheric methane in urban and suburban areas: fossil and non-fossil methane from local sources. Atmos. Environ. 1998, 32 (17), 2947-2955.

(35) Espic, C.; Liechti, M.; Battaglia, M.; Paul, D.; Röckmann, T.; Szidat, S. Compound-Specific Radiocarbon Analysis of Atmospheric Methane: A New Preconcentration and Purification Setup. Radiocarbon 2019, 61 (5), 1461-1476.

(36) Simpson, I. J.; Sulbaek Andersen, M. P.; Meinardi, S.; Bruhwiler, L.; Blake, N. J.; Helmig, D.; Rowland, F. S.; Blake, D. R. Long-Term Decline of Global Atmospheric Ethane Concentrations and Implications for Methane. Nature 2012, 488 (7412), 490-494.

(37) Wunch, D.; Toon, G. C.; Hedelius, J. K.; Vizenor, N.; Roehl, C. M.; Saad, K. M.; Blavier, J.-F. L.; Blake, D. R.; Wennberg, P. O. Quantifying the Loss of Processed Natural Gas within California's South Coast Air Basin Using Long-Term Measurements of Ethane and Methane. Atmos. Chem. Phys. 2016, 16 (22), 14091-14105.

(38) Emission Bilans of Pollutants Greenhouse Gases in Ile-deFrance Region in 2010 and History 2000/2005. Methods and Results; AIRPARIF, 2013.

(39) Paris resigne avec GRDF pour distribuer du gaz, mais plus proper. Le Figaro 2019; https://www.lefigaro.fr/flash-eco/parisresigne-avec-grdf-pour-distribuer-du-gaz-mais-plus-propre-20191115 (accessed Apr 23, 2020).

(40) Polémique sur l'état du réseau de gaz parisien. La Tribune 2019; https://www.latribune.fr/entreprises-finance/industrie/ energie-environnement/polemique-sur-l-etat-du-reseau-de-gazparisien-803664.html (accessed Apr 23, 2020).

(41) [Communiqué de Presse] « Réaction de \#GRDF suite aux propos de Monsieur @A_Vesperini sur la sécurité du réseau \#gaz à \#Paris" \#Trévise \#Explosion \#Paris9. GRDF sur Twitter 2019; https://twitter.com/grdf/status/1084437895841280000/photo/ 1 (accessed Apr 23, 2020).

(42) Scarpelli, T. R.; Jacob, D. J.; Maasakkers, J. D.; Sulprizio, M. P.; Sheng, J. X.; Rose, K.; Romeo, L.; Worden, J. R.; Janssens-Maenhout, G. A Global Gridded $(0.1 \circ \times 0.10)$ Inventory of Methane Emissions from Oil, Gas, and Coal Exploitation Based on National Reports to the United Nations Framework Convention on Climate Change. Earth System Science Data 2020, 12, 563-575.

(43) Analysis of Inventory and Emissions' Cadastres of Principal Greenhouse Gasses in Ile-de-France Region; AIRPARIF, 2005. 